\title{
Functional impairment in patients with major depressive disorder: the 2-year PERFORM study
}

This article was published in the following Dove Press journal:

Neuropsychiatric Disease and Treatment

\author{
Lene Hammer-Helmich' \\ Josep Maria Haro² \\ Bengt Jönsson ${ }^{3}$ \\ Audrey Tanguy Melac ${ }^{4}$ \\ Sylvie Di Nicola ${ }^{5}$ \\ Julien Chollet ${ }^{6}$ \\ Dominique Milea ${ }^{7}$ \\ Benoît Rive ${ }^{8}$ \\ Delphine Saragoussi ${ }^{4}$
}

'Real World Evidence and Epidemiology, H Lundbeck A/S, Valby, Denmark; ${ }^{2}$ Research and Teaching Unit, Parc Sanitari Sant Joan de Deu, CIBERSAM, University of Barcelona, Barcelona, Spain; ${ }^{3}$ Department of Economics, Stockholm School of Economics, Stockholm, Sweden; ${ }^{4}$ Real-World Evidence and Epidemiology, Lundbeck SAS, Issyles-Moulineaux, ${ }^{5}$ Biostatistics, Inferential, Paris, ${ }^{6} \mathrm{Clinical}$ Operations, Lundbeck SAS, Issy-les-Moulineaux, France; ${ }^{7} \mathrm{Health}$ Economics and Epidemiology, Lundbeck Singapore Pte. Ltd, Singapore, Singapore; ${ }^{8} \mathrm{Global}$ Analytics, Lundbeck SAS, Issy-lesMoulineaux, France
Correspondence: Lene Hammer-Helmich Real World Evidence and Epidemiology, H Lundbeck A/S, Ottiliavej 9, 2500 Valby, Denmark

Tel +4530832880

Email leem@lundbeck.com
Background: The Prospective Epidemiological Research on Functioning Outcomes Related to Major depressive disorder (PERFORM) study describes the course of depressive symptoms, perceived cognitive symptoms, and functional impairment over 2 years in outpatients with major depressive disorder (MDD) and investigates the patient-related factors associated with functional impairment.

Methods: This was a 2-year observational study in 1,159 outpatients with MDD aged 18-65 years who were either initiating antidepressant monotherapy or undergoing their first switch of antidepressant. Functional impairment was assessed by the Sheehan Disability Scale and the Work Productivity and Activity Impairment questionnaire. Patients assessed depression severity using the nine-item Patient Health Questionnaire and severity of perceived cognitive symptoms using the five-item Perceived Deficit Questionnaire. To investigate which patientrelated factors were associated with functional impairment, univariate analyses of variance were performed to identify relevant factors that were then included in multivariate analyses of covariance at baseline, month 2, months 6 and 12 combined, and months 18 and 24 combined.

Results: The greatest improvement in depressive symptoms, perceived cognitive symptoms, and functional impairment was seen immediately (within 2 months) following initiation or switch of antidepressant therapy, followed by more gradual improvement and long-term stabilization. Improvement in perceived cognitive symptoms was less marked than improvement in depressive symptoms during the acute treatment phase. Functional impairment in patients with MDD was not only associated with severity of depressive symptoms but also independently associated with severity of perceived cognitive symptoms when adjusted for depression severity throughout the 2 years of follow-up.

Conclusion: These findings highlight the burden of functional impairment in MDD and the importance of recognizing and managing cognitive symptoms in daily practice.

Keywords: major depressive disorder, functioning, functional impairment, depression, cognition

\section{Introduction}

Major depressive disorder (MDD) is a common and debilitating condition that affects more than 120 million people worldwide. ${ }^{1}$ In the European Union, it is estimated that 30 million people aged over 14 years - or $6.9 \%$ of the total population in this age group experience depression during a 12 -month period. ${ }^{2}$ Compared with the general population, patients with MDD report substantial functional impairment. ${ }^{3-8}$ In the Sequenced Treatment Alternatives to Relieve Depression (STAR*D) study, a large US study designed to assess the efficacy of sequential acute treatments for MDD, only $7 \%$ of patients reported within-normal functioning before initiation of antidepressant therapy. ${ }^{8}$ The level of functional impairment associated with depression has been shown to equal or exceed that 
associated with other severe chronic general medical conditions, such as diabetes and congestive heart failure. ${ }^{9}$

Functional impairment in MDD is associated with a considerable social and economic burden. ${ }^{10-13}$ Multiple domains of functioning are typically impaired in patients with MDD, including the ability to perform activities of daily living, the ability to form and maintain interpersonal relationships, and work capacity/productivity. ${ }^{14-16}$ Available data suggest that impaired functioning in patients with MDD can persist even after marked improvement in depressive symptoms..$^{8,14,17-19}$ This is of clinical significance because residual functional impairment has been associated with an increased risk of relapse and recurrence of depression. ${ }^{20,21}$ From a patient's perspective, return to usual levels of functioning may be as important a treatment outcome as resolution of depressive symptoms. ${ }^{22,23}$

To our knowledge, few studies have fully explored the different aspects of functioning in MDD from a patient's perspective, particularly the long-term evolution of functional symptoms during antidepressant treatment and the patientrelated factors that may be associated with this functional impairment. The Prospective Epidemiological Research on Functioning Outcomes Related to Major depressive disorder (PERFORM) study is an observational cohort study undertaken to better understand the course of a depressive episode and its impact on patient functioning over 2 years in outpatients with MDD in routine clinical practice in five European countries. The aims of this study were 1) to describe the course of depressive symptoms, perceived cognitive symptoms, and functional impairment over a 2 -year period in patients with MDD who were either starting their first course of antidepressant monotherapy or undergoing their first switch of antidepressant and 2) to investigate which patient-related factors were associated with this functional impairment.

\section{Methods}

\section{Study design}

PERFORM was a 2-year multicenter, prospective, noninterventional cohort study in outpatients with MDD enrolled by either a general practitioner (GP) or a psychiatrist in five European countries (France, Germany, Spain, Sweden, and the UK; NCT01427439). In each country, the proportion of recruited GPs and psychiatrists was balanced against the national proportions of these clinicians treating patients with depression. Eligible patients were aged 18-65 years, had a current diagnosis of MDD according to the Diagnostic and Statistical Manual of Mental Disorders (4th Edition, Text Revision criteria; confirmed by the Mini International Psychiatric
Interview questionnaire [depression module]), and were either initiating antidepressant monotherapy or undergoing their first switch of antidepressant. The choice of antidepressant prescribed was independent of study participation. Patients receiving antidepressant combination therapy at the time of the initial consultation were excluded from study entry. Patients were also excluded if they had schizophrenia or other nonaffective psychosis, bipolar disorder, substance dependence, mood disorders due to a general medical condition or substances, or dementia or other neurodegenerative diseases that might significantly impact cognitive functioning. Pregnant women and women $\leq 6$ months postpartum were also excluded.

Ethical approval was obtained for each study site in accordance with national regulations regarding observational studies as follows. France: French National Agency for Medicines and Health Products Safety (Agence Nationale de Sécurité du Médicament et des Produits de Santé, previously called Agence Française de Sécurité Sanitaire des Produits de Santé), advisory committee on information processing in material research in the field of health (Comité Consultatif sur le Traitement de l'Information en matière de Recherche dans le domaine de la Santé), French data protection agency (Commission Nationale de l'Informatique et des Libertés), French National Medical Council (Conseil National de l'Ordre des Médecins), Ethics Committee (CPP Ile de France II); 102 physicians/sites. Germany: Munich Ethics Committee, local ethics committees including Hamburg, Rheinland-Pfalz, Sachsen and WestfalenLippe Ethics Committees, and others; 47 physicians/sites. Spain: Agencia Española del Medicamento y Productos Sanitarios, Comités Eticos de Investigaciones Clinicas, Comunidades Autónomas of 14 regions; 46 physicians/sites. Sweden: Uméå Ethics Committee; 22 physicians/sites. UK: Medical Research and Ethics Committee, National Institute for Health Research, and local submissions; 65 physicians/sites.

All included patients provided signed written informed consent for participation.

\section{Study assessments and data collection}

Study assessments and data collection occurred during routine visits within the normal course of care at baseline and approximately 2, 6, 12, 18, and 24 months. Variables documented included demographic information, physical characteristics, history of MDD, characteristics of the current episode of depression, MDD management and health care resource use, and the presence of any other mental disorders or functional syndromes.

Functional impairment was assessed at all visits using the Sheehan Disability Scale (SDS) ${ }^{24}$ and the depression-specific 
version of the Work Productivity and Activity Impairment (WPAI) questionnaire. ${ }^{25}$ The SDS is a brief self-report tool that assesses functional impairment over the previous 7 days in three domains: work/school, social life/leisure activities, and family life/home duties. Patients rate the severity of impairment in each domain on a scale of $0-10$, with higher values indicating greater impairment. Scores for the individual domains can be combined to generate a measure of global functional impairment that ranges from 0 (unimpaired) to 30 (highly impaired). SDS total score was not available for nonworking patients. The SDS has been validated for use in patients with $\mathrm{MDD}^{26}$ and has been widely used in clinical trials. The WPAI questionnaire is a validated short instrument that assesses impairment in work and other regular activities over the past 7 days. The WPAI questionnaire assesses four separate measures: absenteeism (ie, the proportion of work time missed due to MDD), presenteeism (ie, the degree of impairment while working due to MDD), work productivity loss (ie, overall work impairment due to MDD/absenteeism plus presenteeism), and activity impairment (ie, the degree of impairment of regular, nonwork activity due to MDD). WPAI scores are expressed as percent impairment, with higher values indicating greater impairment. The ability to evaluate presenteeism as well as absenteeism is of particular importance in patients with MDD.

Depression severity was assessed by patients using the nine-item Patient Health Questionnaire (PHQ-9). ${ }^{27}$ The PHQ-9 assesses the severity of depressive symptoms over the previous 2 weeks. PHQ-9 total score ranges from 0 (absence of depression) to 27 (severe depression); scores of 5-9, 10-14, 15-19, and $>20$ represent mild, moderate, moderately severe, and severe depression, respectively. Depression severity was also assessed by all participating investigators using the Clinical Global Impression-Severity of illness scale (CGI-S). ${ }^{28}$ CGI-S is a standardized generic assessment tool for rating the severity of an illness on a sevenpoint scale; scores range from 1 (normal, not at all ill) to 7 (among the most extremely ill patients). Cognitive symptoms were assessed by patients using the five-item Perceived Deficit Questionnaire (PDQ-5), which assesses subjective cognitive symptoms (memory, concentration, and executive function) over the past 4 weeks. ${ }^{29,30}$ PDQ-5 total score ranges from 0 to 20, with higher scores reflecting greater severity.

Psychiatrists also assessed depression severity using the Montgomery-Åsberg Depression Rating Scale ${ }^{31}$ and severity of anxiety symptoms using the Hamilton Anxiety Rating Scale. ${ }^{32}$ Other patient-reported questionnaires administered included the Medical Outcomes Study Short-Form (12-item)
Health Survey, ${ }^{33}$ the EuroQol 5-Dimensions Questionnaire (three-level version; in UK patients only), ${ }^{34}$ the Arizona Sexual Experiences Scale, ${ }^{35}$ and the four-item MoriskyGreen Medication Adherence Scale ${ }^{36}$ Data for these scales are not presented in this paper.

\section{Statistical analysis}

The population for analysis comprised all patients who met study inclusion criteria and no exclusion criteria, and who completed a baseline and at least one post-baseline assessment or patient-reported outcome questionnaire. All assessment data were summarized at each time point using descriptive techniques. Continuous variables are presented as mean \pm standard deviation (SD); categorical and binary variables are presented as counts and percentages. To describe the course of functional impairment, depressive symptoms, and perceived cognitive symptoms, SDS total score, WPAI absenteeism and WPAI presenteeism scores, PHQ-9 total score, and PDQ-5 total score were plotted over time from baseline to month 24 .

To investigate which patient-related factors were associated with functional impairment, univariate analyses of variance were performed to identify relevant factors that were then included in multivariate analyses of covariance (ANCOVA). Associations with functional impairment (measured by SDS total score and WPAI scores) were investigated at four time points: baseline, month 2, months 6 and 12 combined, and months 18 and 24 combined. For functional impairment at baseline, associations with other baseline factors were assessed. For analyses of functional impairment at month 2 , month 6/month 12 , and month 18 /month 24 , associations with additional factors at month 2 were assessed as well as associations with baseline factors that were not measured at later time points. Therefore, baseline and month 2 analyses are cross-sectional by nature, whereas month 6/month 12 and month 18/month 24 analyses had a predictive aspect. As data from two visits were included in the month 6/month 12 and month 18/month 24 analyses, a mixed model for repeated measurements including a random effect for patients was used for these analyses.

The factors included in the univariate analyses were selected based on a literature review and clinical experience (Supplementary materials). Factors with $P<0.20$ in the univariate analyses were then selected for the multivariate ANCOVA model to which backward stepwise variable selection was applied (ie, sequential removal of the least significant variable from the model and recomputation of the model until all remaining variables had $P<0.05$ ). Four factors 
were forced into the model because they were identified as potential confounders (country, age, and sex at baseline for analyses at all time points; PHQ-9 total score at baseline for the baseline analyses and at month 2 for analyses at the other time points).

Missing data were not replaced in any of the analyses, ie, all data included in the analyses were observed cases. Analyses were performed using $\mathrm{SAS}^{\circledR}$ statistical software (Version 9.2; SAS Institute Inc., Cary, NC, USA).

\section{Results}

\section{Study population}

A total of 1,895 patients were screened for inclusion in this study, 1,402 of whom were enrolled. The first patient was screened on February 25, 2011, and the last patient completed the study on February 19, 2015. In all, 1,159 patients $(82.7 \%)$ completed the baseline visit and at least one follow-up visit without any violation of inclusion or exclusion criteria and were therefore included in the analyzable population, 862 of whom completed the full 2 years of follow-up. Reasons for exclusion were violation of at least one of the inclusion and/or exclusion criteria at baseline $(n=167)$ and/or lack of post-baseline data $(n=101$, including 76 who met the inclusion criteria at baseline).

Analyzed patients were from the UK (29.4\%), France (29.2\%), Spain (23.3\%), Germany (14.2\%), and Sweden (3.9\%). Most patients were enrolled and followed up by GPs $(83.6 \%)$. In terms of depression history, $56.6 \%$ of patients had experienced a previous depressive episode. Of these, $8.9 \%$ had previously been hospitalized for depression and $13.1 \%$ had previously attempted suicide. In terms of treatment status, $78.7 \%$ of patients were initiating antidepressant treatment at study entry and $21.3 \%$ were switching antidepressant for the first time; treatment status of two patients was unknown. Mean \pm SD age was $44.3 \pm 12.0$ years, and $73.2 \%$ of patients were female.

\section{Functional impairment, depressive symptoms, and perceived cognitive symptoms over time}

At baseline (Table S1), patients reported marked functional impairment (mean \pm SD SDS total score [range: 0-30], 19.2 \pm 6.8 ; mean \pm SD WPAI absenteeism, 32.1\% $\pm 40.2 \%$; mean \pm SD WPAI presenteeism, 48.9\% $\pm 26.9 \%$; mean \pm SD WPAI overall work impairment, 53.5\% $\pm 27.9 \%$; and mean \pm SD WPAI overall activity impairment, $61.1 \% \pm 24.8 \%$ ). Patient-reported MDD severity was moderate to severe (mean \pm SD PHQ-9 score [range: 0-27], 17.6 \pm 5.3 ), and severity of perceived cognitive symptoms was moderate (mean \pm SD PDQ-5 score [range: 0-20], 11.4 44.6 ).

Mean SDS total score, WPAI absenteeism and presenteeism scores, PHQ-9 score, and PDQ-5 score decreased (ie, improved) over the 2 years of follow-up (Table S1). As shown in Figure 1, the greatest reduction in scores generally occurred within 2 months of initiation or switch of antidepressant monotherapy, with scores tending to plateau after 6-12 months. Rate of change was slower for the PDQ-5 score than for other outcomes.

\section{Factors associated with functional impairment}

Results of the univariate analyses undertaken to identify relevant patient-related factors for inclusion in the multivariate analyses are summarized in Tables S2-S5. Results of the final multivariate analyses undertaken to investigate the patient-related factors associated with functional impairment at baseline, month 2 , month 6/month 12 , and month 18 / month 24 are shown in Tables 1-4.

\section{Baseline}

In the final multivariate model at baseline (Table 1), depression severity (PHQ-9 total score) was significantly associated with functional impairment (SDS total score and all WPAI scores, all $P<0.001)$. Severity of perceived cognitive symptoms (PDQ-5 total score) was significantly associated with SDS total score and all WPAI scores except absenteeism (all $P<0.001$ ). The only other factor found to be significantly associated $(P<0.05)$ with SDS total score and all WPAI scores at baseline was country. No other factors were found to be significantly associated with more than three of the five functional outcomes at this time point.

\section{Month 2}

In the final multivariate model at month 2 (Table 2), PHQ-9 score at month 2 was significantly associated with SDS total score and all WPAI scores except absenteeism (all $P<0.001$ ) and PDQ-5 score at month 2 was significantly associated with SDS total score and all WPAI scores $(P=0.021$ for WPAI absenteeism score and $P<0.001$ for all other scores). No other factors were found to be significantly associated $(P<0.05)$ with more than three of the five functional outcomes at this time point.

\section{Month 6/month 12}

In the final multivariate model at month 6/month 12 (Table 3), PHQ-9 score at month 2 was significantly associated with 

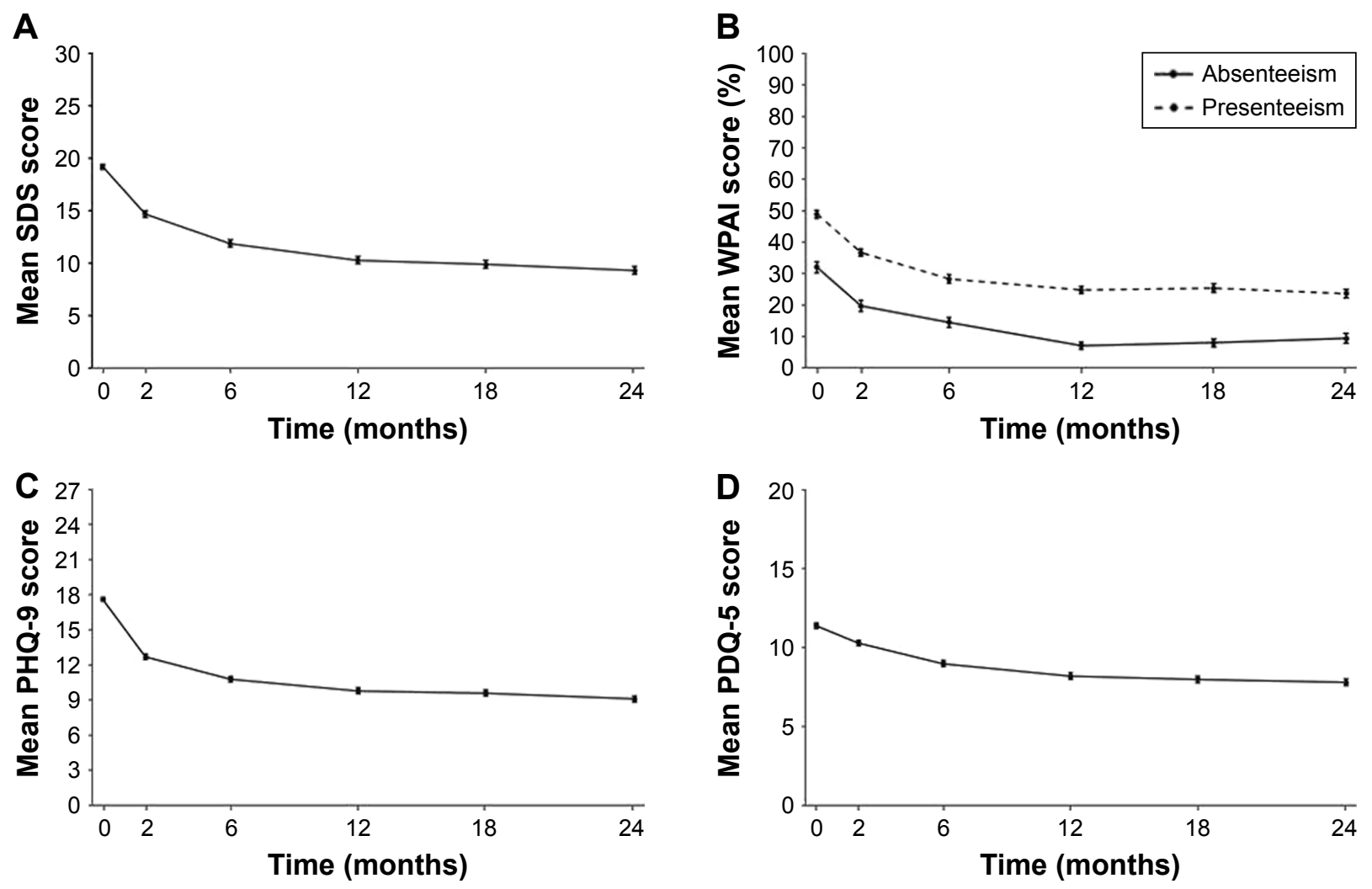

Figure I Changes from baseline to month 24 in: (A) SDS total score (range 0-30), (B) WPAl absenteeism and presenteeism scores (range 0-100), (C) PHQ-9 total score (range 0-27), and (D) PDQ-5 total score (range 0-20; analyzable population; $\mathrm{N}=1,159$ ).

Notes: Data are mean \pm standard error; higher scores indicate worse outcomes.

Abbreviations: PDQ-5, five-item Perceived Deficit Questionnaire; PHQ-9, nine-item Patient Health Questionnaire; SDS, Sheehan Disability Scale; WPAI, Work Productivity and Activity Impairment.

SDS total score and all WPAI scores $(P<0.001)$ and PDQ-5 score at month 2 was significantly associated with SDS total score and all WPAI scores except absenteeism $(P \leq 0.006)$. No other factors were found to be significantly associated $(P<0.05)$ with more than three of the five functional outcomes at this time point.

\section{Month $18 /$ month 24}

In the final multivariate model at month 18 /month 24 (Table 4), PHQ-9 score at month 2 was significantly associated with SDS total score and all WPAI scores except absenteeism $(P<0.001)$, and PDQ-5 score at month 2 was significantly associated with SDS total score $(P=0.001)$, WPAI overall work impairment $(P=0.046)$, and WPAI activity impairment $(P<0.001)$. No other factors were found to be significantly associated $(P<0.05)$ with three or more of the five functional outcomes at this time point.

\section{Discussion}

Long-term evolution of depression severity and functional outcomes have seldom been described in patients with MDD and, to our knowledge, long-term evolution of perceived cognitive symptoms has not been previously assessed. PERFORM is a large international observational study undertaken to better understand the course of a depressive episode and its impact on functioning over a 2-year period in patients with MDD initiating or switching antidepressant monotherapy in routine clinical practice in five European countries. Marked functional impairment was evident in the study cohort at baseline. Greatest improvement in depressive symptoms and functioning was seen during the acute phase of treatment (ie, within 2 months of antidepressant initiation or switch), followed by more gradual improvement during the maintenance phase (2-6 months), and stabilization over the long-term phase (6-24 months). Improvement in cognitive symptoms was less marked during the acute treatment phase, suggesting that current treatments may be less effective for cognitive symptoms. Other studies have shown that cognitive symptoms persist longer than depressive symptoms in patients with MDD and that these residual cognitive symptoms can persist even in patients who achieve clinical remission. ${ }^{37,38}$ Furthermore, in a previous analysis, residual perceived cognitive symptoms in patients who achieved remission of depression at month 2 in the PERFORM study 
Table I Factors associated with functional impairment at baseline in the final multivariate analysis

\begin{tabular}{|c|c|c|c|c|c|}
\hline Factor $^{a}$ & $\begin{array}{l}\text { SDS total } \\
\text { score } \\
(\mathrm{N}=560)\end{array}$ & $\begin{array}{l}\text { WPAl absenteeism } \\
\text { score } \\
(\mathbf{N}=420)\end{array}$ & $\begin{array}{l}\text { WPAI presenteeism } \\
\text { score } \\
(\mathbf{N}=\mathbf{3 7 2})\end{array}$ & $\begin{array}{l}\text { WPAI overall } \\
\text { work impairment } \\
\text { score }(\mathrm{N}=328)\end{array}$ & $\begin{array}{l}\text { WPAl activity } \\
\text { impairment } \\
\text { score }(\mathrm{N}=704)\end{array}$ \\
\hline Country & $* *$ & $* * *$ & $* *$ & * & $* * *$ \\
\hline Age (years) & NS & NS & NS & $*$ & $*$ \\
\hline Sex & NS & NS & NS & NS & NS \\
\hline Educational level & - & - & $*$ & $* * *$ & - \\
\hline Elementary school & & & $-5.52 \pm 3.44$ & $-5.09 \pm 3.92$ & \\
\hline High school & & & $-7.83 \pm 2.95$ & $-10.43 \pm 3.25$ & \\
\hline Non-university degree & & & $-9.65 \pm 3.51$ & $-15.04 \pm 3.84$ & \\
\hline University degree & & & - & - & \\
\hline Switch of antidepressant & * & - & - & - & * \\
\hline Switch & $\mathrm{I} . \mathrm{II} \pm 0.56$ & & & & $4.07 \pm 1.91$ \\
\hline Non-switch & - & & & & \\
\hline $\begin{array}{l}\text { At least one other } \\
\text { concomitant mental disorder }\end{array}$ & $*$ & - & $*$ & - & - \\
\hline Yes & $1.40 \pm 0.63$ & & $7.68 \pm 3.70$ & & \\
\hline No & - & & - & & \\
\hline Chronic fatigue & - & - & $*$ & $* *$ & - \\
\hline Yes & & & $8.06 \pm 3.64$ & $12.09 \pm 4.27$ & \\
\hline No & & & - & - & \\
\hline $\begin{array}{l}\text { Sick leave within the past } \\
12 \text { months before baseline }\end{array}$ & $* *$ & $* * *$ & - & ** & - \\
\hline Yes & $1.29 \pm 0.48$ & $33.70 \pm 3.68$ & & $8.44 \pm 2.90$ & \\
\hline No & - & - & & - & \\
\hline PHQ-9 total score & $* * *$ & $* * *$ & $* * *$ & $* * *$ & $* * *$ \\
\hline $0-4$ & $-17.30 \pm 2.35$ & $-31.27 \pm 20.83$ & $-44.89 \pm 11.33$ & $-49.50 \pm 13.60$ & $-55.28 \pm 9.09$ \\
\hline $5-9$ & $-9.59 \pm 0.96$ & $-26.58 \pm 6.78$ & $-24.36 \pm 4.62$ & $-28.47 \pm 5.19$ & $-31.68 \pm 3.37$ \\
\hline $10-14$ & $-5.58 \pm 0.68$ & $-17.56 \pm 4.96$ & $-15.53 \pm 3.63$ & $-16.32 \pm 4.05$ & $-23.54 \pm 2.43$ \\
\hline $15-19$ & $-3.21 \pm 0.54$ & $-7.20 \pm 4.16$ & $-1.85 \pm 2.88$ & $1.17 \pm 3.26$ & $-10.84 \pm 1.87$ \\
\hline $20-27$ & - & - & - & - & - \\
\hline PDQ-5 score & $* * *$ & - & $* * *$ & $* * *$ & $* * *$ \\
\hline $0-7$ & $-5.32 \pm 0.77$ & & $-23.98 \pm 3.98$ & $-20.2 I \pm 4.4 I$ & $-14.55 \pm 2.70$ \\
\hline $8-11$ & $-2.67 \pm 0.64$ & & $-10.32 \pm 3.49$ & $-7.12 \pm 3.90$ & $-8.87 \pm 2.25$ \\
\hline $12-14$ & $-2.15 \pm 0.60$ & & $-|1.78 \pm 3.4|$ & $-9.87 \pm 3.78$ & $-6.24 \pm 2.11$ \\
\hline $15-20$ & - & & - & - & - \\
\hline
\end{tabular}

Notes: Coefficient ( \pm standard error) is given. Factors with $P<0.2$ in the univariate ANOVA were retained in the multivariate ANCOVA (final model). Factors highlighted in gray are those forced in the multivariate analysis; - indicates that the factor listed was either not included or not kept in the final model for that outcome; - indicates reference category. $* \mathrm{P}<0.05$; $* * \mathrm{P}<0.01$; $* * * P<0.00$ I. aBaseline characteristic unless otherwise stated.

Abbreviations: ANCOVA, analyses of covariance; ANOVA, analyses of variance; NS, not significant; PDQ-5, five-item Perceived Deficit Questionnaire; PHQ-9, nine-item Patient Health Questionnaire; SDS, Sheehan Disability Scale; WPAI, Work Productivity and Activity Impairment.

were found to be associated with an increased risk of relapse at month $6 .{ }^{39}$ Such findings highlight the need for long-term treatment of patients with MDD and are indicative of unmet treatment needs in this population.

The observed association between depression severity (PHQ-9 score) and functional impairment at baseline and at almost all subsequent visits over the 2 years of follow-up was expected and is consistent with the results of previous studies. ${ }^{40-44}$ Perceived severity of cognitive symptoms (PDQ-5 score) also showed a strong association with functional impairment at all time points in this study when adjusted for severity of depression. This finding is consistent with previous data showing that cognitive symptoms have a major impact on functional recovery in MDD. ${ }^{45,46}$ Residual cognitive symptoms have also been shown to be a principal mediator of occupational impairment in patients with remitted MDD. ${ }^{47,48}$ In our study, perceived cognitive symptoms were found to be more strongly associated with presenteeism than with absenteeism. This is not unexpected, particularly over the long duration of follow-up in this study, as patients may be reluctant to disclose their diagnosis to their employer and/or be unable to take prolonged sick leave due to economic considerations. Other studies have shown presenteeism to be a greater problem than absenteeism in patients with MDD. ${ }^{49-51}$ 
Table 2 Factors associated with functional impairment at month 2 in the final multivariate analysis

\begin{tabular}{|c|c|c|c|c|c|}
\hline Factor $^{\mathrm{a}}$ & $\begin{array}{l}\text { SDS total score } \\
(\mathbf{N}=\mathbf{4 2 8})\end{array}$ & $\begin{array}{l}\text { WPAI absenteeism } \\
\text { score }(\mathbf{N}=\mathbf{2 9 9})\end{array}$ & $\begin{array}{l}\text { WPAl presenteeism } \\
\text { score }(\mathbf{N}=\mathbf{2 9 5})\end{array}$ & $\begin{array}{l}\text { WPAI overall work } \\
\text { impairment score } \\
(\mathrm{N}=\mathbf{2 5} \mathrm{I})\end{array}$ & $\begin{array}{l}\text { WPAl activity } \\
\text { impairment score } \\
(\mathrm{N}=582)\end{array}$ \\
\hline Country & NS & NS & ** & * & NS \\
\hline Age (years) & NS & NS & $*$ & $* *$ & NS \\
\hline Sex & $*$ & NS & NS & NS & NS \\
\hline $\begin{array}{l}\text { At least one other concomitant } \\
\text { mental disorder }\end{array}$ & - & - & $* *$ & $*$ & - \\
\hline Yes & & & $9.42 \pm 3.65$ & $10.89 \pm 4.34$ & \\
\hline No & & & - & - & \\
\hline $\begin{array}{l}\text { Hospitalization for depression } \\
\text { between baseline and month } 2\end{array}$ & - & $*$ & - & - & - \\
\hline Yes & & $33.60 \pm 15.22$ & & & \\
\hline No & & - & & & \\
\hline $\begin{array}{l}\text { Sick leave within the past } 12 \text { months } \\
\text { before baseline or at baseline or } \\
\text { between baseline and month } 2\end{array}$ & $*$ & $* * *$ & - & - & - \\
\hline Yes & $1.15 \pm 0.53$ & $17.84 \pm 3.98$ & & & \\
\hline No & - & - & & & \\
\hline CGI-S score at month 2 & $* * *$ & $*$ & - & - & $*$ \\
\hline $1-3$ & $-3.88 \pm 0.88$ & $-17.79 \pm 6.95$ & & & $-6.6 I \pm 2.76$ \\
\hline 4 & $-2.40 \pm 0.87$ & $-14.63 \pm 7.05$ & & & $-4.03 \pm 2.74$ \\
\hline $5-7$ & - & - & & & - \\
\hline PHQ-9 total score at month 2 & $* * *$ & NS & $* * *$ & $* * *$ & $* * *$ \\
\hline $0-4$ & $-13.04 \pm 1.42$ & & $-39.45 \pm 6.29$ & $-36.35 \pm 7.34$ & $-46.03 \pm 4.14$ \\
\hline $5-9$ & $-8.63 \pm 1.02$ & & $-24.00 \pm 4.69$ & $-21.95 \pm 5.53$ & $-29.08 \pm 3.11$ \\
\hline $10-14$ & $-6.14 \pm 0.93$ & & $-13.92 \pm 4.54$ & $-15.05 \pm 5.32$ & $-18.97 \pm 2.87$ \\
\hline $15-19$ & $-1.96 \pm 0.88$ & & $-4.5 I \pm 4.53$ & $-5.12 \pm 5.39$ & $-9.24 \pm 2.77$ \\
\hline $20-27$ & - & & - & - & - \\
\hline PDQ-5 score at month 2 & $* * *$ & $*$ & $* * *$ & $* * *$ & $* * *$ \\
\hline $0-7$ & $-6.34 \pm 0.91$ & $-20.79 \pm 6.94$ & $-25.39 \pm 4.05$ & $-24.96 \pm 4.67$ & $-22.88 \pm 2.84$ \\
\hline $8-11$ & $-2.88 \pm 0.83$ & $-14.53 \pm 6.05$ & $-18.59 \pm 3.66$ & $-19.16 \pm 4.15$ & $-13.30 \pm 2.57$ \\
\hline $12-14$ & $-2.26 \pm 0.77$ & $-8.08 \pm 5.77$ & $-\mid 0.14 \pm 3.51$ & $-7.16 \pm 4.06$ & $-9.19 \pm 2.38$ \\
\hline $15-20$ & - & - & - & - & - \\
\hline
\end{tabular}

Notes: Coefficient ( \pm standard error) is given. Factors with $P<0.2$ in the univariate ANOVA were retained in the multivariate ANCOVA (final model). Factors highlighted in gray are those forced in the multivariate analysis; - indicates that the factor listed was either not included or not kept in the final model for that outcome; - indicates reference category. $* P<0.05 ; * * P<0.01$; $* * * P<0.001$; a Baseline characteristic unless otherwise stated.

Abbreviations: ANCOVA, analyses of covariance; ANOVA, analyses of variance; CGI-S, Clinical Global Impression-Severity of illness scale; NS, not significant; PDQ-5, fiveitem Perceived Deficit Questionnaire; PHQ-9, nine-item Patient Health Questionnaire; SDS, Sheehan Disability Scale; WPAI, Work Productivity and Activity Impairment.

The only other factor found to be significantly associated with all functional outcomes was country at the baseline visit. This association most likely stems from differences in clinical and administrative practices between the countries, such as differences in the proportion of patients treated by psychiatrists and national regulations regarding sick leave. No other patient-related factor was found to be associated with more than three of the five functional outcomes at any time point.

Strengths of this study are that it was performed in a real-world setting with longitudinal follow-up of a large cohort of patients, the majority of whom were enrolled and followed up by GPs. Indeed, study sites were balanced with the national proportions of these clinicians treating patients with depression to ensure study findings were applicable to routine practice. Sociodemographic and clinical characteristics of enrolled patients were as expected for a depressive population. ${ }^{52}$ Further strengths include the long duration of follow-up and the wide range of assessments performed, including the use of patient-reported outcomes to capture the impact of MDD from the patient's own perspective.

A potential limitation of the study is that cognitive symptoms were assessed using a patient-reported questionnaire, thus providing an assessment of subjective (perceived) rather than objective cognitive dysfunction. In addition, patients' 
Table 3 Factors associated with functional impairment at months 6 and 12 combined in the final multivariate analysis (MMRM)

\begin{tabular}{|c|c|c|c|c|c|}
\hline Factor $^{a}$ & $\begin{array}{l}\text { SDS total score } \\
(\mathbf{N}=703)^{\mathrm{b}}\end{array}$ & $\begin{array}{l}\text { WPAI } \\
\text { absenteeism score } \\
(\mathrm{N}=47 \mathrm{I})^{\mathrm{b}}\end{array}$ & $\begin{array}{l}\text { WPAl presenteeism } \\
\text { score }(\mathrm{N}=504)^{\mathrm{b}}\end{array}$ & $\begin{array}{l}\text { WPAI overall work } \\
\text { impairment score } \\
(\mathrm{N}=431)^{\mathrm{b}}\end{array}$ & $\begin{array}{l}\text { WPAl activity } \\
\text { impairment score } \\
(\mathrm{N}=921)^{\mathrm{b}}\end{array}$ \\
\hline Country & * & NS & NS & NS & **** \\
\hline Age (years) & NS & NS & NS & NS & NS \\
\hline Sex & * & NS & $* * *$ & $*$ & NS \\
\hline Chronic pain or fibromyalgia & $*$ & - & $*$ & $* *$ & - \\
\hline Yes & $\mathrm{I} .7 \mathrm{I} \pm 0.73$ & & $6.48 \pm 2.97$ & $9.91 \pm 3.52$ & \\
\hline No & - & & - & - & \\
\hline $\begin{array}{l}\text { Suicide attempt before baseline or } \\
\text { between baseline and month } 2\end{array}$ & NS & - & - & - & - \\
\hline $\begin{array}{l}\text { Sick leave within the past } 12 \text { months } \\
\text { before baseline or at baseline or } \\
\text { between baseline and month } 2\end{array}$ & - & $* *$ & - & - & - \\
\hline Yes & & $6.87 \pm 2.60$ & & & \\
\hline No & & - & & & \\
\hline CGI-S score at month 2 & $* * *$ & - & - & - & $*$ \\
\hline $1-3$ & $-3.64 \pm 0.95$ & & & & $-8.07 \pm 3.05$ \\
\hline 4 & $-2.90 \pm 0.95$ & & & & $-3.56 \pm 3.03$ \\
\hline $5-7$ & - & & & & - \\
\hline PHQ-9 total score at month 2 & $* * *$ & $* * *$ & $* * *$ & $* * *$ & $* * *$ \\
\hline $0-4$ & $-10.66 \pm 1.47$ & $-31.58 \pm 5.7 \mid$ & $-32.27 \pm 5.94$ & $-26.64 \pm 6.76$ & $-33.92 \pm 4.57$ \\
\hline $5-9$ & $-8.43 \pm 1.13$ & $-28.68 \pm 4.43$ & $-21.52 \pm 4.60$ & $-17.45 \pm 5.37$ & $-31.45 \pm 3.42$ \\
\hline $10-14$ & $-6.15 \pm 1.04$ & $-27.11 \pm 4.39$ & $-12.31 \pm 4.43$ & $-8.20 \pm 5.16$ & $-23.18 \pm 3.15$ \\
\hline $15-19$ & $-3.15 \pm 1.02$ & $-21.57 \pm 4.60$ & $-9.74 \pm 4.39$ & $-4.54 \pm 5.31$ & $-10.66 \pm 3.11$ \\
\hline $20-27$ & - & - & - & - & - \\
\hline PDQ-5 score at month 2 & $* * *$ & - & $* *$ & $* *$ & $* * *$ \\
\hline $0-7$ & $-5.97 \pm 1.04$ & & $-15.54 \pm 4.10$ & $-16.57 \pm 4.64$ & $-15.41 \pm 3.19$ \\
\hline $8-11$ & $-3.06 \pm 0.92$ & & $-10.86 \pm 3.64$ & $-10.23 \pm 4.16$ & $-8.49 \pm 2.83$ \\
\hline $12-14$ & $-3.06 \pm 0.88$ & & $-8.52 \pm 3.56$ & $-7.70 \pm 4.05$ & $-8.12 \pm 2.66$ \\
\hline $15-20$ & - & & - & - & - \\
\hline
\end{tabular}

Notes: Coefficient ( \pm standard error) is given. Factors with $P<0.2$ in the univariate ANOVA were retained in the multivariate ANCOVA (final model). Factors highlighted in gray are those forced in the multivariate analysis; - indicates that the factor listed was either not included or not kept in the final model for that outcome; - indicates reference category. $* P<0.05 ; * * P<0.01$; $* * * P<0.001$. aBaseline characteristic unless otherwise stated. ${ }^{b}$ Sum of the number of patients at the two visits.

Abbreviations: ANCOVA, analyses of covariance; ANOVA, analyses of variance; CGI-S, Clinical Global Impression-Severity of illness scale; MMRM, mixed model for repeated measurements; NS, not significant; PDQ-5, five-item Perceived Deficit Questionnaire; PHQ-9, nine-item Patient Health Questionnaire; SDS, Sheehan Disability Scale; WPAI, Work Productivity and Activity Impairment.

occupations and job-related stress levels were not taken into account in the various analyses, and these factors could potentially have an impact on functioning and work impairment. Further limitations are that the study only recruited outpatients who were initiating antidepressant monotherapy or switching antidepressant monotherapy for the first time; hence, the study results cannot be generalized to the entire MDD population in Europe, particularly those at a later disease stage or receiving psychotherapy. The discrepancy in the number of patients included between countries should also be taken into consideration in terms of generalization of the study findings.

\section{Conclusion}

In summary, results of this large 2-year European observational study highlight the substantial functional burden of MDD. Greatest improvement in depressive symptoms and functional impairment was seen immediately following initiation or switch of antidepressant monotherapy, followed by more gradual improvement and long-term stabilization; improvement in cognitive symptoms was less marked during the acute treatment phase. Functional impairment in patients with MDD was found to be not only associated with severity of depressive symptoms but also independently associated with subjective cognitive symptoms when adjusted for depression severity throughout the 2 years of follow-up. These findings highlight the importance of recognizing cognitive symptoms in patients with MDD in daily practice and suggest that treatment interventions that specifically target cognitive symptoms may improve functional recovery in this population. 
Table 4 Factors associated with functional impairment at months 18 and 24 combined in the final multivariate analysis (MMRM)

\begin{tabular}{|c|c|c|c|c|c|}
\hline Factor $^{\mathrm{a}}$ & $\begin{array}{l}\text { SDS total score } \\
(\mathrm{N}=621)^{b}\end{array}$ & $\begin{array}{l}\text { WPAI absenteeism } \\
\text { score }(\mathbf{N}=5 \text { I } 8)^{\mathrm{b}}\end{array}$ & $\begin{array}{l}\text { WPAI presenteeism } \\
\text { score }(\mathbf{N}=459)^{b}\end{array}$ & $\begin{array}{l}\text { WPAI overall work } \\
\text { impairment score } \\
(\mathrm{N}=403)^{\mathrm{b}}\end{array}$ & $\begin{array}{l}\text { WPAl activity } \\
\text { impairment score } \\
(\mathrm{N}=804)^{\mathrm{b}}\end{array}$ \\
\hline Country & NS & NS & NS & NS & NS \\
\hline Age (years) & NS & NS & NS & NS & NS \\
\hline Sex & NS & NS & NS & NS & NS \\
\hline Chronic pain or fibromyalgia & $* *$ & - & - & $*$ & $*$ \\
\hline Yes & $2.56 \pm 0.85$ & & & $7.05 \pm 3.46$ & $5.34 \pm 2.60$ \\
\hline No & - & & & - & - \\
\hline $\begin{array}{l}\text { Suicide attempt before baseline } \\
\text { or between baseline and month } 2\end{array}$ & - & - & - & - & * \\
\hline Yes & & & & & $10.66 \pm 4.20$ \\
\hline No & & & & & - \\
\hline PHQ-9 total score at month 2 & $* * *$ & NS & $* * *$ & $* * *$ & $* * *$ \\
\hline $0-4$ & $-9.75 \pm 1.65$ & & $-33.89 \pm 5.83$ & $-19.41 \pm 7.24$ & $-33.31 \pm 5.20$ \\
\hline $5-9$ & $-8.20 \pm 1.26$ & & $-26.69 \pm 4.22$ & $-|7.5| \pm 5.38$ & $-28.23 \pm 3.95$ \\
\hline $10-14$ & $-7.09 \pm 1.20$ & & $-22.8 \mathrm{I} \pm 4.22$ & $-10.61 \pm 5.32$ & $-24.03 \pm 3.75$ \\
\hline $15-19$ & $-3.14 \pm 1.18$ & & $-10.18 \pm 4.42$ & $-0.17 \pm 5.17$ & $-13.36 \pm 3.63$ \\
\hline $20-27$ & - & & - & - & - \\
\hline PDQ-5 score at month 2 & $* * *$ & - & - & $*$ & $* * *$ \\
\hline $0-7$ & $-4.60 \pm 1.20$ & & & $-9.59 \pm 4.53$ & $-15.72 \pm 3.67$ \\
\hline $8-11$ & $-3.10 \pm 1.10$ & & & $-8.42 \pm 4.14$ & $-10.27 \pm 3.32$ \\
\hline $12-14$ & $-1.66 \pm 1.05$ & & & $-1.09 \pm 4.09$ & $-4.6 I \pm 3.15$ \\
\hline $15-20$ & - & & & - & - \\
\hline
\end{tabular}

Notes: Coefficient ( \pm standard error) is given. Factors with $P<0.2$ in the univariate ANOVA were retained in the multivariate ANCOVA (final model). Factors highlighted in gray are those forced in the multivariate analysis; - indicates that the factor listed was either not included or not kept in the final model for that outcome; - indicates reference category. $* P<0.05 ; * * P<0.01$; $* * * P<0.001$. aBaseline characteristic unless otherwise stated. bSum of the number of patients at the two visits.

Abbreviations: ANCOVA, analyses of covariance; ANOVA, analyses of variance; MMRM, mixed model for repeated measurements; NS, not significant; PDQ-5, five-item Perceived Deficit Questionnaire; PHQ-9, nine-item Patient Health Questionnaire; SDS, Sheehan Disability Scale; WPAI, Work Productivity and Activity Impairment.

\section{Acknowledgments}

This study was funded by Lundbeck SAS. The authors thank Professor Martin Knapp (Personal Social Services Research Unit, London School of Economics and Political Science, UK) for his advice regarding the study design and interpretation of the study findings. The authors also thank Mapi for logistical management of the study. The authors would also like to express their gratitude to all the patients and physicians who participated in the study. Writing and editorial assistance was provided by Jennifer Coward of Anthemis Consulting Ltd, funded by Lundbeck SAS.

\section{Disclosure}

LHH is a full-time employee of Lundbeck A/S. JMH has received honoraria for being an advisor or providing educational talks for Lundbeck, Otsuka, Roche, and Eli Lilly and Company. BJ has received honoraria for being an advisor to Lundbeck. SDN is a shareholder of Inferential, Paris, France, a provider of biostatistical consulting services working with pharmaceutical companies including Lundbeck. ATM, JC, DM, BR, and DS were full-time employees of Lundbeck at the time this study was conducted. ATM has also been an employee of AbbVie Inc. The authors report no other conflicts of interest in this work.

\section{References}

1. Kessler RC, Birnbaum HG, Shahly V, et al. Age differences in the prevalence and co-morbidity of DSM-IV major depressive episodes: results from the WHO World Mental Health Survey Initiative. Depress Anxiety. 2010;27(4):351-364.

2. Wittchen HU, Jacobi F, Rehm J, et al. The size and burden of mental disorders and other disorders of the brain in Europe 2010. Eur Neuropsychopharmacol. 2011;21(9):655-679.

3. Hirschfeld RM, Dunner DL, Keitner G, et al. Does psychosocial functioning improve independent of depressive symptoms? A comparison of nefazodone, psychotherapy, and their combination. Biol Psychiatry. 2002;51(2):123-133.

4. Kennedy BL, Lin Y, Schwab JJ. Work, social, and family disabilities of subjects with anxiety and depression. South Med J. 2002;95(12): 1424-1427.

5. Kessler RC, Berglund P, Demler O, et al. The epidemiology of major depressive disorder: results from the National Comorbidity Survey Replication (NCS-R). JAMA. 2003;289(23):3095-3105.

6. Srisurapanont M, Hong JP, Tian-Mei S, et al. Clinical features of depression in Asia: results of a large prospective, cross-sectional study. Asia Pac Psychiatry. 2013;5(4):259-267.

7. Lin C, Yen Y, Chen M, Chen C. Depression and pain impair daily functioning and quality of life in patients with major depressive disorder. J Affect Disord. 2014;166:173-178.

8. IsHak WW, James DM, Mirocha J, et al. Patient-reported functioning in major depressive disorder. Ther Adv Chronic Dis. 2016;7(3):160-169. 
9. Hays RD, Wells KB, Sherbourne CD, Rogers W, Spritzer K. Functioning and well-being outcomes of patients with depression compared with chronic general medical illnesses. Arch Gen Psychiatry. 1995; 52(1):11-19.

10. Katon W. The impact of depression on workplace functioning and disability costs. Am J Manag Care. 2009;15(11 Supp1):S322-S327.

11. Birnbaum HG, Kessler RC, Kelley D, Ben-Hamadi R, Joish VN, Greenberg PE. Employer burden of mild, moderate, and severe major depressive disorder: mental health services utilization and costs, and work performance. Depress Anxiety. 2010;27(1):78-89.

12. Gelenberg AJ. The prevalence and impact of depression. J Clin Psychiatry. 2010;71(3):e06.

13. Kessler RC. The costs of depression. Psychiatr Clin North Am. 2012; 35:1-14.

14. McKnight PE, Kashdan TB. The importance of functional impairment to mental health outcomes: a case for reassessing our goals in depression treatment research. Clin Psychol Rev. 2009;29(3):243-259.

15. Greer TL, Kurian BT, Trivedi MH. Defining and measuring functional recovery from depression. CNS Drugs. 2010;24(4):267-284.

16. Woo JM, Kim W, Hwang TY, et al. Impact of depression on work productivity and its improvement after outpatient treatment with antidepressants. Value Health. 2011;14(4):475-482.

17. Israel JA. Remission in depression: definition and initial treatment approaches. J Psychopharmacol. 2006;20(3 Suppl):5-10.

18. Kennedy N, Foy K, Sherazi R, McDonough M, McKeon P. Long-term social functioning after depression treated by psychiatrists: a review. Bipolar Disord. 2007;9(1-2):25-37.

19. Trivedi MH, Morris DW, Wisniewski SR, et al. Increase in work productivity of depressed individuals with improvement in depressive symptom severity. Am J Psychiatry. 2013;170(6):633-641.

20. Solomon DA, Leon AC, Endicott J, et al. Psychosocial impairment and recurrence of major depression. Compr Psychiatry. 2004;45(6): 423-430.

21. Hardeveld F, Spijker J, De Graaf R, Nolen WA, Beekman AT. Prevalence and predictors of recurrence of major depressive disorder in the adult population. Acta Psychiatr Scand. 2010;122(3):184-191.

22. Zimmerman M, McGlinchey JB, Posternak MA, Friedman M, Attiullah N, Boerescu D. How should remission from depression be defined? The depressed patient's perspective. Am J Psychiatry. 2006;163:148-150.

23. Langlieb AM, Guico-Pabia CJ. Beyond symptomatic improvement: assessing real-world outcomes in patients with major depressive disorder. Prim Care Companion J Clin Psychiatry. 2010;12(2):e1-e14.

24. Sheehan DV, Harnett-Sheehan K, Raj BA. The measurement of disability. Int Clin Psychopharmacol. 1996;11(Suppl 3):89-95.

25. Reilly MC, Zbrozek AS, Dukes EM. The validity and reproducibility of a work productivity and activity impairment instrument. Pharmacoeconomics. 1993;4(5):353-365.

26. Sheehan KH, Sheehan DV. Assessing treatment effects in clinical trials with the discan metric of the Sheehan Disability Scale. Int Clin Psychopharmacol. 2008;23(2):70-83.

27. Kroenke K, Spitzer RL, Williams JB. The PHQ-9: validity of a brief depression severity measure. J Gen Intern Med. 2001;16(9): 606-613.

28. Guy W. Clinical Global Impressions. ECDEU Assessment Manual for Psychopharmacology. Rockville, USA: National Institute of Mental Health; 1976.

29. Sullivan MJ, Edgley K, Dehoux E. A survey of multiple sclerosis. Part 1. Perceived cognitive problems and compensatory strategy use. Can J Rehabil. 1990;4(2):99-105.

30. National Multiple Sclerosis Society. Multiple Sclerosis Quality of Life Inventory: A User's Manual. New York, USA: The Consortium of Multiple Sclerosis Centers Health Services Research Subcommittee, The National Multiple Sclerosis Society; 1997.

31. Montgomery SA, Åsberg M. A new depression scale designed to be sensitive to change. Br J Psychiatry. 1979;134:382-389.

32. Hamilton M. The assessment of anxiety states by rating. Br J Med Psychol. 1959;32(1):50-55.
33. Ware J Jr, Kosinski M, Keller SD. A 12-item short-form health survey: construction of scales and preliminary tests of reliability and validity. Med Care. 1996;34(3):220-233.

34. EuroQol Group. EuroQol - a new facility for the measurement of health-related quality of life. Health Policy. 1990;16(3):199-208.

35. McGahuey CA, Gelenberg AJ, Laukes CA, et al. The Arizona Sexual Experience Scale (ASEX): reliability and validity. $J$ Sex Marital Ther. 2000;26(1):25-40.

36. Morisky DE, Green LW, Levine DM. Concurrent and predictive validity of a self-reported measure of medication adherence. Med Care. 1986;24(1):67-74.

37. Conradi HJ, Ormel J, de Jonge P. Presence of individual (residual) symptoms during depressive episodes and periods of remission: a 3-year prospective study. Psychol Med. 2011;41(6):1165-1174.

38. Hasselbalch BJ, Knorr U, Kessing LV. Cognitive impairment in the remitted state of unipolar depressive disorder: a systematic review. $J$ Affect Disord. 2011;134(1-3):20-31.

39. Saragoussi D, Touya M, Haro JM, et al. Factors associated with failure to achieve remission and with relapse after remission in patients with major depressive disorder in the PERFORM study. Neuropsychiatr Dis Treat. 2017;13:2151-2165.

40. Adler DA, McLaughlin TJ, Rogers WH, Chang H, Lapitsky L, Lerner D. Job performance deficits due to depression. Am J Psychiatry. 2006; 163(9):1569-1576.

41. Rytsälä HJ, Melartin TK, Leskelä US, Lestelä-Mielonen PS, Sokero TP, Isometsä ET. Determinants of functional disability and social adjustment in major depressive disorder: a prospective study. J Nerv Ment Dis. 2006;194(8):570-576.

42. Naismith SL, Longley WA, Scott EM, Hickie IB. Disability in major depression related to self-rated and objectively-measured cognitive deficits: a preliminary study. BMC Psychiatry. 2007;7:32.

43. Iosifescu DV. The relation between mood, cognition and psychosocial functioning in psychiatric disorders. Eur Neuropsychopharmacol. 2012;22(Suppl 3):S499-S504.

44. Kim JM, Chalem Y, di Nicola S, Hong JP, Won SH, Milea D. A crosssectional study of functional disabilities and perceived cognitive dysfunction in patients with major depressive disorder in South Korea: the PERFORM-K study. Psychiatry Res. 2016;239:353-361.

45. Jaeger J, Berns S, Uzelac S, Davis-Conway S. Neurocognitive deficits and disability in major depressive disorder. Psychiatry Res. 2006;145(1): $39-48$.

46. McIntyre RS, Cha DS, Soczynska JK, et al. Cognitive deficits and functional outcomes in major depressive disorder: determinants, substrates, and treatment interventions. Depress Anxiety. 2013;30(6):515-527.

47. Bortolato B, Carvalho AF, McIntyre RS. Cognitive dysfunction in major depressive disorder: a state-of-the-art clinical review. CNS Neurol Disord Drug Targets. 2014;13(10):1804-1818.

48. Woo YS, Rosenblat JD, Kakar R, Bahk WM, McIntyre RS. Cognitive deficits as a mediator of poor occupational function in remitted major depressive disorder patients. Clin Psychopharmacol Neurosci. 2016;14(1):1-16.

49. Stewart WF, Ricci JA, Chee E, Hahn SR, Morganstein D. Cost of lost productive work time among US workers with depression. JAMA. 2003;289(23):3135-3144.

50. Sanderson K, Andrews G. Common mental disorders in the workforce: recent findings from descriptive and social epidemiology. Can $J$ Psychiatry. 2006;51(2):63-75.

51. Evans-Lacko S, Knapp M. Global patterns of workplace productivity for people with depression: absenteeism and presenteeism costs across eight diverse countries. Soc Psychiatry Psychiatr Epidemiol. 2016; 51(11):1525-1537.

52. Martín-Merino E, Ruigómez A, Johansson S, Wallander MA, GarcíaRodriguez LA. Study of a cohort of patients newly diagnosed with depression in general practice: prevalence, incidence, comorbidity, and treatment patterns. Prim Care Companion J Clin Psychiatry. 2010; 12(1):PCC.08m00764. 
Neuropsychiatric Disease and Treatment

Dovepress

\section{Publish your work in this journal}

Neuropsychiatric Disease and Treatment is an international, peerreviewed journal of clinical therapeutics and pharmacology focusing on concise rapid reporting of clinical or pre-clinical studies on a range of neuropsychiatric and neurological disorders. This journa is indexed on PubMed Central, the 'PsycINFO' database and CAS,

and is the official journal of The International Neuropsychiatric Association (INA). The manuscript management system is completely online and includes a very quick and fair peer-review system, which is all easy to use. Visit http://www.dovepress.com/testimonials.php to read real quotes from published authors.

Submit your manuscript here: http://www.dovepress.com/neuropsychiatric-disease-and-treatment-journal 